\title{
CORRECTION
}

\section{Correction to: Economic Evaluations of Childhood Hearing Loss Screening Programmes: A Systematic Review and Critique}

\author{
Rajan Sharma $^{1}$ (D) Yuanyuan Gu ${ }^{1,2} \cdot$ Teresa Y. C. Ching $^{3} \cdot$ Vivienne Marnane $^{3} \cdot$ Bonny Parkinson $^{1}$
}

Published online: 1 March 2019

(c) Springer Nature Switzerland AG 2019

\section{Correction to: Applied Health Economics and Health Policy https://doi.org/10.1007/s40258-018-00456-1}

The third author's first name should have been spelled "Teresa" rather than "Theresa".

The original article has been corrected.

The original article can be found online at https://doi.org/10.1007/ s40258-018-00456-1.

\section{Rajan Sharma}

rajan.sharma1@students.mq.edu.au

1 Macquarie University Centre for the Health Economy, Sydney, NSW, Australia

2 Department of Economics and Related Studies, University of York, York, UK

3 National Acoustic Laboratories, Australian Hearing Hub, Sydney, NSW, Australia 